\title{
La formación de los futuros docentes. Entre historia, competitividad, e incertidumbre
}

\section{The training of future teachers. Between history, competitiveness, and uncertainty}

\author{
Martín Muñoz Mancilla \\ Instituto Tecnológico de Úrsulo Galván: Úrsulo Galvan, Veracruz, México.
}

\section{Resumen}

Objetivo: Analizar los rasgos de los modelos de docentes en la historia de la educación en México para poder retomar elementos que permitan comprender su complejidad en un nuevo contexto caracterizado por la globalización, el neoliberalismo y los avances científicos y tecnológicos. Método: Se ubica dentro del enfoque cualitativo, los autores analizados fueron: Woods (1987), Goetz y Lecompte (1988), Clifford (2001), Álvarez- Gayou (2003), y Geertz (2003), entre otros. A fin de comprender cómo hacer visible lo invisible, y dar voz a los participantes. Las estrategias utilizadas fueron: la observación, la entrevista y las historias de vida, posteriormente, se cruzó información con el análisis de planes y programas de estudio utilizados en las escuelas normales mediante matrices de análisis. Resultados: Entre los principales hallazgos se destaca la evolución de la formación docente de acuerdo con el marco político, económico e ideológico. En ese sentido, "vocación," "compromiso," "solidaridad," "promoción de la justicia social," se transformaron gradualmente. Conclusión: Se ha pasado de ser emancipador de la justicia social, a un técnico de la enseñanza, posteriormente a facilitador de aprendizajes y en los últimos años a ser competente con nuevos rasgos de: "calidad," "eficiencia," "eficacia," y "equidad," en un ambiente de incertidumbre.

Palabras clave: Formación de docentes, historia, incertidumbre.

\section{Abstract}

Objective: Analyze the features of teacher models in the history of education in Mexico to be able to take up elements that allow understanding its complexity in a new context characterized by globalization, neoliberalism and scientific and technological advances. Method: It is located within the qualitative approach, the authors analyzed were: Woods (1987), Goetz and Lecompte (1988), Clifford (2001), Álvarez-Gayou (2003), and Geertz (2003), among others. In order to try to understand how to make visible the invisible, and give voice to the participants. The strategies used were: observation, interview and life histories, later, information was crossed with the analysis of plans and study programs used in normal schools through analysis matrices. Results: Among the main findings is the evolution of teacher training in accordance with the political, economic and ideological framework. In that sense, "vocation," "commitment," "solidarity," "promotion of social justice," were gradually transformed. Conclusion: It has gone from being an emancipator of social justice, to a technician of education, later to facilitator of learning and in recent years to be competent with new features of: "quality," "efficiency," "effectiveness," and "equity," in an environment of uncertainty.

\author{
Open Access: \\ ISSN: 0124-2121 \\ E-ISSN: $2665-2420$ \\ Editor: \\ Patricia Martínez Barrios \\ Universidad Simón Bolivar \\ Correspondencia: \\ Martín Muñoz \\ martinmum_m@y \\ ahoo.com.mx \\ Recibido: 07-05-18 \\ Aceptado: 25-08-18 \\ Publicado: 12-12-18 \\ DOI: \\ http:/10.17081/eduhu \\ m.21.36
}

Copyright (C 2019 Educación y Humanismo

Keywords: Teacher training, history, uncertainty. 


\section{Introducción}

Se destaca la necesidad de reflexionar sobre los rasgos de un modelo de docente en el siglo XXI, dado que en los últimos años para poder llegar a ser un docente idóneo y competente se debe cumplir con lo estipulado en una normatividad donde se contempla una evaluación diseñada por "expertos."

Dicha evaluación para los docentes contempla no sólo un examen de ingreso al servicio profesional docente, sino también de permanencia en el servicio. Por las características de la evaluación requiere que los docentes sean disciplinados, sistemáticos y organizados, para que gradualmente vayan construyendo sus evidencias de trabajo, las vayan analizando, fundamentando y recopilando para su presentación correspondiente.

El proceso evaluativo llega a promover en la mayoría de los docentes: preocupación, nerviosismo, ansiedad, inquietud, zozobra, estrés, e incertidumbre, por lo que para poder cumplir con los requerimientos requieren de tiempo y constancia, de ahí las horas de desvelo, de sacrificio al esparcimiento, e incluso al tiempo de convivencia con la familia y los amigos.

La manera en que se evalúa a los maestros ha causado debate, polémica, incertidumbre e incluso en algunos lugares se ha cuestionado de manera personal o en grandes grupos de maestros la forma en la que se desarrolla, incluso se han dado grandes manifestaciones de rechazo. Estos eventos han sido ampliamente difundidos a través de las redes sociales.

Ante dicha realidad, en esta coyuntura de crisis del Estado de bienestar; de debilitamiento de las políticas nacionales; de privatización de bienes y servicios; de supresión de los derechos legados por las Revoluciones de cada uno de los países; de predominio de inseguridad; de manera contradictoria para algunos han surgido algunas oportunidades que permiten mejorar sus situaciones de vida.

Con la finalidad de evitar hablar de los rasgos de los nuevos docentes desde lo que se dice a través de los diversos medios oficiales de información, donde se tiende a estigmatizar a través de diversas imágenes, como: impulsivos, imprudentes, insensatos, necios, violentos, irresponsables, sin argumentos, y negligentes a la evaluación.

Ante esta paradójica situación resulta pertinente y necesario realizar un rastreo histórico a través de las diferentes etapas evolutivas por las que ha pasado la formación de docentes en México, y así retomar algunos elementos para comprender el presente y poder vislumbrar el futuro (Bloch, 1952). 
Con la finalidad de lograr una explicación lógica y congruente se dividió la exposición en los subtemas: Método, Desarrollo, Conclusiones y Referencias. Se parte de algunas preguntas de investigación, un supuesto y un propósito tal y como se desarrollan en el siguiente apartado.

\section{Método}

¿Cuáles han sido los rasgos más significativos en los modelos de docentes que se han desarrollado en la historia de la educación en México? ¿Cómo ha cambiado la realidad social en los últimos años y su manifestación en los rasgos de los docentes? O planteando la pregunta con otras palabras, ¿Cuáles son los requerimientos y desafíos que deben poseer los docentes en este nuevo contexto caracterizado por la globalización, el neoliberalismo y los avances científicos y tecnológicos?

Después de haber planteado dichas interrogantes se construyó el siguiente supuesto:

Si bien, la globalización, el neoliberalismo y los avances científicos y tecnológicos han transformado estructuralmente la realidad social, gracias a la puesta en marcha del modelo de formación basado en competencias, de políticas de competitividad, y de la privatización de bienes y servicios; sin embargo, en su desempeño laboral algunos docentes por su actitud retoman algunos rasgos prevalecientes en los modelos docentes que promovieron la identidad y desarrollo nacional, tales como: el ser altruista, comprometido, emancipador social, crítico, ético, promotor de justicia y con la intención de formarse de manera académica, crítica y profesional.

El enfoque con el que se desarrolló la investigación fue cualitativo. De acuerdo con Álvarez-Gayou (2003), consiste en hacer visible lo invisible y tratar de dar voz a los sujetos, por tanto es descriptiva e interpretativa (Eisner, 1990). Las técnicas utilizadas fueron: la observación, la entrevista, las historias de vida, y el trabajo de grupo focal con docentes y docentes jubilados.

Asimismo, se retomaron elementos analíticos conceptuales mediante la revisión de libros y diversos documentos, tales como: los planes y programas de estudio del Gobierno del Estado de México (1973), (1975), y de la Secretaría de Educación Pública (1984), (1997), (2012) y (2018), los cuáles han sido aplicado en las escuelas normales de México, así como de los acuerdos en los que se han sustentado. 


\section{Desarrollo}

Dada la diversidad de información recabada fue necesario organizar la exposición mediante los siguientes apartados: a) Los primeros maestros con rasgos de apóstoles y misioneros; b) La transformación de promotores de la justicia por profesionales de la educación; c) La evolución del tecnólogo al docente investigador; d) Los organismos internacionales con el modelo de formación por competencias y un nuevo docente competente, tal y como se exponen a continuación.

\section{a) Los primeros maestros con rasgos de apóstoles y misioneros}

Se partió de reconocer que durante la época de la colonia los evangelizadores se desempeñaron como educadores con la finalidad de difundir la religión católica, para esto resultaba necesario enseñar a leer y a escribir a algunos indígenas de la Nueva España (Gonzálbo, 1985). Fue hasta la época de la Independencia cuando se inició a cuestionar y debatir quienes serían las personas ideales para poder educar a los habitantes de la naciente nación Mexicana (Tank, 1999).

De acuerdo con Meneses (1988a), (1988b) y Tenti (1999), se dio una pugna entre los grupos de conservadores contra los liberales, los primeros proponían a la Iglesia para que permaneciera con la responsabilidad de educar a los mexicanos; en cambio, los segundos promovieron que el Estado fuera el responsable de integrar un sistema educativo nacional y fundara nuevas instituciones educativas.

A decir de Jiménez (1998), gracias al triunfo del grupo de los liberales se organizó dicho proyecto y se invitó a destacados intelectuales con pensamiento liberal, tales como el maestro alemán Enrique C. Rébsamen y el político y escritor mexicano Ignacio Manuel Altamirano quienes oficialmente fundaron las primeras instituciones educativas donde se formarían los nuevos maestros.

A dichas instituciones se les denominó Escuelas Normales basándose en el nombre del modelo educativo francés, donde se les otorgó por su connotación etimológica, dado que proviene de "norma," "modelo", "directriz." Por tanto, históricamente en dichas instituciones educativas se empezaron a formar los nuevos maestros para la educación básica de acuerdo con las políticas de los Estados nacionales.

Como se viene destacando, en el caso de México la primera escuela normal se fundó en Jalapa Veracruz por el maestro Alemán Enrique C. Rébsamen en 1886. La segunda en la Ciudad de México, por el abogado, escritor y político mexicano Ignacio Manuel Altamirano 
en 1887. Ambas instituciones se caracterizaron por promover una ideología liberal en los nuevos docentes para que al incorporarse al campo laboral la difundieran por todo el territorio nacional.

De acuerdo con Corro (1964) y Hermida (1986), la formación docente durante el Porfiriato tuvo estrecha relación con la teoría educativa proveniente de Europa, incluso se integró en planes y programas el aprendizaje del inglés y francés para que los futuros docentes analizaran a los autores representativos de escuelas de pensamiento en su versión original.

Años después, ante la desigualdad prevaleciente y la inconformidad generalizada del país, el pueblo se levantó en armas en búsqueda de una mayor igualdad y justicia social; en lo que se denominó Revolución Mexicana. Finalmente culminó con el destierro del dictador y la promulgación de ciertas demandas como derechos en la Constitución Política de los Estados Unidos Mexicanos de 1917 (Const., 1917).

Uno de los derechos donde se promovió lograr una mayor justicia social fue el referente a la educación, específicamente el artículo tercero constitucional, donde se destacó: laicidad, gratuidad y obligatoriedad. El responsable de consolidar dicho proyecto fue el político y escritor José Vásconselos, quien ante la ignorancia y fanatismo prevaleciente se inspiró en los misioneros. De manera semejante los maestros de ese entonces deberían de entregarse en cuerpo y alma a la labor de la enseñanza y al progreso del pueblo.

Así pues, del porfiriato a la época posrevolucionaria y del paso del modelo de apóstol de la enseñanza a misionero, prevalecieron en los docentes rasgos de: "compromiso", "entrega", "dedicación", "esfuerzo", "sacrificio", "penitencia" , "amor", "fe" y "esperanza". Años después, seguían siendo retomados, tal y como fue en el sexenio del Presidente Lázaro Cárdenas y de manera gradual se empezaron a integrar otros.

Sin duda alguna, fue en el periodo denominado Cardenismo cuando los rasgos de los docentes fueron cercanos al progreso de los mexicanos, dado que fueron considerados líderes sociales, emancipador de la justicia social, promotores del desarrollo del pueblo y del reparto agrario; así pues, su responsabilidad no sólo eran la impartición de los conocimientos escolares, sino que su trabajo rebasaba el aula dado lo sociopolítico; situación que se va a transformar en las siguientes décadas, tal y como se expone en el siguiente apartado. 


\section{b) La transformación de promotores de la justicia por profesionales de la educación}

Recapitulando los apartados anteriores, desde sus orígenes los docentes en México estuvieron relacionados con compromisos similares al de los religiosos; sin embargo, en la época posrevolucionaria se le vinculó con el desarrollo y progreso del pueblo, por lo que su trabajo rebasó el espacio escolar.

A decir de Meneses (1988c), durante la década de los años treinta, específicamente durante el gobierno del General Lázaro Cárdenas se promovió un modelo docente de "líder social", se pretendió que los docentes fueran los encargados de inculcar el proyecto político y ser los promotores de una mayor justicia social. Por tanto, combatieron los cacicazgos prevalecientes, la ignorancia, los fanatismos y fueron impulsores del reparto agrario; sin embargo, resulta pertinente destacar que muchos de ellos perdieron la vida en el cumplimiento de sus deberes y obligaciones.

En la década de los cuarenta varios fenómenos transformaron la realidad del país, tales como: la culminación de la Segunda Guerra Mundial; el triunfo del General Manuel Ávila Camacho y la incorporación de nuevas políticas; así como la inversión extranjera y la industrialización del país. Ante dicha realidad una gran cantidad de la población emigró del campo a la ciudad en busca de mejores condiciones de vida.

De acuerdo con Arnaut (1998), en la década de los cuarenta no sólo cambió el rol de los docentes quedando atrás trabajo sociopolítico y se encaminó hacia el trabajo escolar, sino que también se redujo su campo de acción evolucionando de lo social a las cuatro paredes del aula. A partir de esta década los nuevos docentes se encaminaron a su desarrollo profesional, al conocimiento de: métodos, técnicas, procedimientos y contenidos.

En ese sentido, los rasgos de "emancipador de la justicia social," "luchador por los intereses y necesidades del pueblo", fueron desplazados por nuevos rasgos, tales como: "poseedor de conocimientos," "dominio de técnicas," y sobre todo una nueva caracterización, como: "el que sabe qué y cómo enseñar" (Oliveros, 1975). Elementos que se van a fortalecer para las siguientes décadas.

Resulta complejo interpretar la década de los cuarenta dados los múltiples factores, tales como: la culminación de la Segunda Guerra Mundial, la llegada de inversionistas a nuestro país, la creciente industrialización, la demanda de mano de obra y sobre todo las

políticas de pacificación social que planteo el Presidente Manuel Ávila Camacho 
denominada: "Unidad Nacional."

En ese sentido la educación y con ello la formación de profesores empezaron a retomar las políticas de los organismos internacionales. Así pues, gradualmente fueron quedando atrás no sólo el perfil docente comprometido por la justicia social, sino también la escuela rural mexicana, por la formación de un técnico de la enseñanza y centros escolares cada vez más urbanizados, tal y como se expone a continuación.

\section{c) La evolución del tecnólogo al docente investigador}

Con base a las reflexiones de Estrada (1992), Reyes (1988) y Alanís (2003), se puede sustentar que el paso del proyecto socialista del presidente Lázaro Cárdenas, al de unidad nacional del Presidente Manuel Ávila Camacho fue un parteaguas en la historia de México y en la formación y responsabilidades de los docentes.

A partir de los años cuarenta se inició a destacar la importancia de profesionalizar a los docentes, a invertir en mayores espacios y recursos para su formación, y así poder estar al mismo nivel académico que los docentes de otros países. Bajo esta lógica se desarrolla durante las siguientes décadas.

En algunos países de Europa y principalmente en Estados Unidos estaba en boga la tecnología educativa y el conductismo mediante las aportaciones de destacados psicólogos, tales como: Skiner (1971), Pavlov (1997), entre otros. Por lo que con la finalidad de estar en correspondencia con políticas educativas internacionales en México se retomaron algunos elementos para la una nueva reforma educativa.

Fue hasta la década de los setenta cuando dicha reforma, priorizó el aprendizaje comprendido cambio de conducta, la utilización de las tecnologías de la enseñanza y la evaluación permanente. Los rasgos del modelo de docente aludieron más al de un tecnólogo de la educación, con adjetivos tales, como: "el que sabe utilizar la tecnología en la enseñanza," "el que domina técnicas de enseñanza," y "el conductor de la enseñanza."

Dicho modelo de enseñanza perduró durante más de dos décadas; sin embargo, a principios de los ochenta empezó a ser seriamente cuestionado, gracias a las aportaciones de autores como: Ausubel (1983), Vigotsky (1995), Bruner (1995), y Piaget (2009), quienes sustentaron que el aprendizaje se construye, por tanto, gracias a dichas aportaciones se pudo sustentar que los docentes no deben ser los "conductores de la enseñanza", sino los "facilitadores del aprendizaje". 
En esa lógica, de acuerdo con Oikión (2008), Rosales (2008) y Hernández (2006), en la década de los ochenta se reformaron las instituciones formadoras de docentes, se reconoce a las escuelas normales como instituciones de educación superior, por lo que su perfil de egresó pretendió formar un docente investigador con rasgos de: "crítico", "analítico" y "reflexivo" a fin de poder transformar su práctica cotidiana mediante el desarrollo de la investigación educativa.

Por tanto, las aportaciones del constructivismo le dieron nuevos rasgos a los docentes, tales como: "facilitador de los aprendizajes," "acompañantes de sus alumnos en los procesos de formación," "promotores y animadores en la comunidades de aprendizaje", entre otros.

Sin embargo, de manera gradual las políticas nacionales tuvieron mayor influencia de los organismos internacionales; ante dicha nueva realidad resulta necesario reflexionar sobre la educación, tal y como se hace en el siguiente apartado.

\section{d) Los organismos internacionales con el modelo de formación por competencias y un nuevo docente competente}

Lo expuesto sustenta cómo desde los orígenes del sistema educativo mexicano y hasta la década de los treinta, las políticas educativas correspondieron a intereses nacionales. A partir de la década de los cuarenta de manera gradual los organismos internacionales empezaron a tener mayores injerencias en las políticas educativas nacionales gracias a diversas recomendaciones.

Después de la culminación de la Segunda Guerra Mundial los países vencedores como fueron Estados Unidos, e Inglaterra y demás países con la finalidad de reconstruir Europa crean algunos organismos tales como: el Banco Mundial (BM), el Fondo Monetario Internacional (FMI) y la Organización para la Cooperación y Desarrollo Económico (OCDE).

A decir de Lerner (2009), dichos organismos internacionales también tuvieron injerencia en América Latina desde los cincuenta y sesenta con la puesta en práctica de las teorías como el keyneisianismo con la finalidad de un mayor desarrollo económico y la reducción la pobreza.

De acuerdo con Peet (2003), se ha concentrado el poder en unas pocas instituciones quienes tienen un control y reglamentación cuasi estatal de planes y programas económicos, quienes ejercen influencia en todo el mundo, también se le conoce como globalización neoliberal. Esta propuesta suprime al modelo keynesiano y la regulación del 
Estado de bienestar o benefactor.

La puesta en marcha de políticas neoliberales da una mayor apertura y libertad a la inversión económica y se reduce la capacidad del Estado (Beck, 1998) y (Baricco, 2004). Este proyecto se consolidó en EU dónde se promovió el sueño americano y un mayor consumismo, por lo que se difunde a nivel internacional por un grupo de expertos desde Washington.

Dichos organismos internacionales han hecho recomendaciones e imposiciones similares a los países que han solicitado y obtenidos créditos económicos. Ante estas condiciones a los deudores se ha ido unificando la economía mundial basada en los tratados de libre comercio y en la apertura económica.

Según Laval (2004) y Coraggio (1997), los organismos internacionales han promovido una educación encaminada al mercado laboral. Las nuevas reformas se fundamentan mediante el modelo de formación por competencias, comprendidas éstas como un conjunto de saberes, conocimientos, actitudes y valores, las cuáles priorizan el saber hacer y la formación para el trabajo en búsqueda de la calidad.

De acuerdo con estudios internacionales Peet (2003), y Laval (2004), así como nacionales como: De la torre (2004), Pérez (2007) y Muñoz (2013), (2015), Muñoz y Rodríguez (2017), Muñoz y Robles (2017), con la puesta en marcha de políticas neoliberales se han desplazado de los planes y programas de estudio algunas asignaturas que priorizaban una mayor formación académica; es decir, aquellas relacionadas con una mayor teoría educativa, filosofía e investigación educativa; en cambio, se han priorizado algunas asignaturas más instrumentales, encaminadas al trabajo, en el caso de las normales a la práctica docente.

El nuevo docente de la época neoliberal de acuerdo con la revisión y análisis de planes y programas de estudio de las escuelas normales, lo novedoso resulta ser la adquisición de elementos para la utilización de las tecnologías de la información, el aprendizaje del inglés como segunda lengua, y la educación socioemocional. Elementos básicos para desarrollar su futura práctica profesional.

El nuevo docente también es sujeto de evaluación y para poder llegar a ser competente e idóneo debe de cumplir con ciertos perfiles, parámetros e indicadores propuestos desde la administración nacional. Dicho proceso ha sido severamente cuestionado en la realidad, dado que el ser buen docente no basta con aprobar un examen, sino también se requieren diversos procesos en el aula de trabajo, como: dominio de estrategias de enseñanza y 
aprendizaje, tacto pedagógico, ética y sobre todo compromiso con alumnos, docentes, padres de familia y la sociedad en general; rasgos de modelo de docente que han estado en la historia y como diría Arnaut (1998), algunos de ellos persisten disfrazados a través del tiempo.

Al paso de la modernidad a la posmodernidad, o como diría Bauman (2004), (2006) y (2008), el paso de la vida sólida a la líquida, el paso del Estado de bienestar a la puesta en marcha de políticas neoliberales ha cambiado la sociedad en general, la educación y al trabajo docente en particular. En esta nueva época predomina: inseguridad, incertidumbre, duda, dilema, conflicto y ya nada es seguro. Por tanto, la seguridad laboral que tuvieron los docentes en tiempos pasados se está diluyendo.

\section{Discusiones y conclusiones}

Cómo se destacó el paso de la modernidad a la posmodernidad, ha traído cambios estructurales en todos los sentidos. En el trabajo docente aquel pasado glorioso por el significativo papel para poder superar la ignorancia, los fanatismos y los cacicazgos fue en parte gracias al compromiso, dedicación, empatía, perseverancia y formación de los docentes.

En el caso de la historia en México los rasgos de los maestros han estado en estrecha correspondencia con el desarrollo y progreso nacional, por ejemplo: "compromiso", "solidaridad", "empatía", "promoción de la equidad" y "justicia social", aunadas a la "preparación y formación académica" han sido parte del involucramiento al trabajo social; sin embargo, en los últimos años mediante la puesta en marcha de políticas neoliberales se han reducido los roles sociales de los maestros y de manera paradójica se ha multiplicado lo administrativo y la priorización de: "calidad," "eficacia," y "eficiencia."

Con base a éste análisis se puede concluir, que de manera impositiva y no consensuada a través del tiempo se han ido transformando los rasgos de los maestros de manera significativa su campo de acción se ha reducido y se han impuesto nuevas normatividades; contradictoriamente, en lugar de preocuparse y dedicarse más porque sus alumnos aprendan tienden a ocuparse por recopilación de evidencias y aprobación de las evaluaciones.

Esta realidad tiende a favorecer la incertidumbre, dado que si no logran aprobar los 
exámenes de ingreso y permanencia serán considerados no idóneos y no podrán poder ejercer la docencia. Así pues, dicho análisis histórico permitió sustentar que los rasgos de los maestros del siglo XXI van mucho más allá de la aprobación de una evaluación, será necesario conocer y revalorar el pasado y así obtener elementos que permitan comprender e interpretar la pertinencia de los valores y su compromiso en el modelo de futuro docente quien se desarrolla entre la historia, competitividad, y la incertidumbre

\section{Referencias}

Alanís, A. (2003). El sistema de formación de maestros en México. México: Trillas.

Álvarez-Gayou, J. (2003).Cómo hacer investigación cualitativa. Fundamentos y metodología. España: Paidós.

Arnaut, A. (1998). Historia de una profesión. Los maestros de educación primaria en México, 1887-1994. México: SEP.

Ausubel, D. (1983). Psicología Educativa. México: Trillas.

Bauman, Z. (2004). Vidas despreciadas: la modernidad y sus parias. España: Paidós.

Bauman, Z. (2006). La globalización. Consecuencias humanas. México: FCE

Bauman, Z. (2008). Trabajo, consumismo y nuevos pobres. México: Gedisa.

Baricco, A. (2004). Sobre la globalización y el mundo que viene. Barcelona: Anagrama.

Beck. U. (1998). ¿Qué es la globalización? Falacias del globalismo, respuestas a la globalización. México: Paidós.

Bloch, M. (1952). Introducción a la historia. México: Breviarios del FCE.

Bruner, J. (1995). Desarrollo cognitivo y educación. España: Morata.

Clifford, J. (2001). Dilemas de la cultura antropológica. Antropología, literatura y arte en la perspectiva posmoderna. Barcelona: Gedisa.

Constitución Política de los Estados Unidos Mexicanos [Const.] (1917) 2da Ed. Gedisa. 
Coraggio, J. L. (1997). La educación según el Banco Mundial. Un análisis de sus propuestas y métodos. Madrid: Miño y Dávila.

Corro, O. (1964). La enseñanza normal en Veracruz. México: Gobierno de Veracruz.

De la Torre, G. M. (2004). Del humanismo a la competitividad. México: UNAM.

Eisner, E. (1990). El ojo ilustrado. Indagación cualitativa y mejora de la práctica educativa. México: Paidós.

Estrada, A. (1992). La formación de maestros en México. Evolución y contexto social. México: Centro de Investigaciones Educativas de la Escuela Normal de Querétaro.

Geertz, C. (2003). La interpretación de las culturas. Barcelona: Gedisa.

Goetz, J. \& Lecompte (1988). Etnografía y diseño cualitativo en la investigación educativa. España: Morata.

Gobierno del Estado de México. (1973). Plan de estudios de la carrera de profesor de educación primaria. México: GEM.

Gobierno del Estado de México. (1975). Plan de estudios Reestructurado de la carrera de profesor de educación primaria. México: GEM.

Gonzálbo, P. (1985). El orden que los religiosos tienen que enseñar a los indios la doctrina y otras cosas de policía cristiana. En El humanismo y la educación en la Nueva España. México: SEP-Caballito.

Hermida, A. (1986). La fundación de la Escuela Normal Veracruzana. México: Fundación de la Escuela Normal Veracruzana.

Hernández, G. (2006). Origen y desarrollo de la educación normal en el estado de México. México: GEM.

Jiménez, A. (1998). La Escuela Nacional de Maestros. Sus orígenes. México: Departamento de Investigaciones Educativas del Cinvestav.

Laval, C. (2004). La escuela no es una empresa. España: Paidós.

Lerner, B. (2009). Banco Mundial: modelo de desarrollo y propuesta educativa. México: Bonilla Artigas. 
Meneses, E. (1988a). Tendencias educativas oficiales en México 1821-1911. México: CEEUAIA.

Meneses, E. (1988b). Tendencias educativas oficiales en México 1811-1934. México: CEEUIA.

Meneses, E. (1998c). Tendencias educativas oficiales en México 1934-1964. México: CEEUIA.

Muñoz. M. (2013). Evolución de la formación de docentes para la educación básica: De líder social a competente. En Carrillo, J. et al. Formación docente: Reflexiones desde diversas perspectivas. México: REDIE. Disponible en http://www.redie.mx/librosyrevistas/libros/forma_doc.pdf\#page=44

Muñoz M. (2015). Autorregulación académica en los procesos de formación docente de las escuelas normales. En Hernández Jácques,L. F. Autorregulación Académica. Investigación sobre perspectiva docente. Durango: REDIE. Disponible en http://iunaes.mx/wp-content/uploads/2015/05/Libro-1.-Autorregulaci\%C3\%B3nAcad\%C3\%A9mica.-Investigaciones-sobre-la-perspectiva-docente.pdf

Muñoz, M. \& Rodríguez, E. (2017a). La Formación en Investigación Educativa: ¿Requerimiento o competencia profesional para los docentes del siglo XXI? En Barraza, A. El Estudio de la Realidad Educativa a partir de sus actores. Durango: Instituto Universitario Anglo Español. Disponible en http://redie.mx/librosyrevistas/libros/estudioreali.pdf\#page $=49$

Muñoz, M. \& Robles, P. (2017b). La educación ambiental en la formación de docentes. Caso escuelas normales de México. En Calixto, R. \& Moreno, L. (Coord.), Educación Ambiental en las Instituciones de Educación Superior (pp. 107 -130). Durango: REDIE. $\quad$ Disponible en https://www.researchgate.net/profile/Raul_Calixto_Flores/publication/320992274_ EDUCACION_AMBIENTAL_EN_LAS_INSTITUCIONES_DE_EDUCACION_SUPERIOR/li nks/5a063494a6fdcc65eab190aa/EDUCACION-AMBIENTAL-EN-LASINSTITUCIONES-DE-EDUCACION-SUPERIOR.pdf

Oikión, G. (2008). El proceso curricular normalista del 84: un acercamiento desde la perspectiva de sus actores. México: UPN.

Oliveros, A. (1975). Los profesores iberoamericanos de educación primaria. Planes de estudio de su formación. Perspectivas Pedagógicas (39), 359-365

Pavlov, I. (1997). Los reflejos condicionados. España: Morata. 
Peet, R. (2003). La Maldita Trinidad. El Fondo Monetario Internacional, El Banco Mundial y la Organización para la Cooperación y Desarrollo Económico. Navarra: Ediciones Laoetot.

Pérez, D. (2007). Filosofía, teoría e investigación en las maestrías en Educación: un campo sobredeterminado. México: PyV.

Piaget, J. (2009). La psicología de la inteligencia. Barcelona: Editorial Crítica.

Reyes, R. (1988). La formación de los maestros en la década de los cuarenta, Pedagogía. Revista de la UPN, 5(16), 12-23.

Rosales, M. (2008). La formación profesional del docente de primaria. México: PyV.

Skiner, B. C. (1971). Ciencia y conducta humana. Barcelona: Fontamara.

Secretaría de Educación Pública (1984). Plan de Estudios de la licenciatura en Educación Primaria. México: Talleres de Litografía.

Secretaría de Educación Pública (1997). Plan y programa de estudios de la Licenciatura en Educación. México: SEP.

Secretaría de Educación Pública (2012). Plan y programas de estudio de la Licenciatura en Educación Primaria. México: SEP.

Secretaría de Educación Pública (2018). Plan y programas de estudio de la Licenciatura en Educación Primaria. México: SEP.

Tank, D. (1999). La educación ilustrada. 1786-1836. México: Colegio de México.

Tenti, E. F. (1999). El arte del buen maestro. México: Pax.

Vigotsky, L. (1995). Pensamiento y lenguaje. España: Paidós.

Woods, P. L. (1987). La escuela por dentro. La etnografía en la investigación educativa. España: Paidós. 